\title{
ANALISIS PENAWARAN TENAGA KERJA WANITA MIGRAN KABUPATEN SUMBAWA
}

\author{
Fitriah Permata Cita ${ }^{1^{*}}$, Mujiburrahmat ${ }^{2}$, Didi Suwardi ${ }^{3}$ \\ ${ }^{1 *}$ Fakultas Ekonomi dan Bisnis Universitas Teknologi Sumbawa \\ ${ }^{2}$ Fakultas Ekonomi dan Bisnis Universitas Teknologi Sumbawa \\ ${ }^{3}$ Fakultas Ekonomi dan Bisnis Universitas Teknologi Sumbawa \\ *Corresponding Author email: ${ }^{1}$ fitriah.permata.cita@uts.ac.id, ${ }^{2}$ mujiburrahmat@uts.ac.id
}

Diterima
Bulan Januari
2020

Diterbitkan
Bulan Februari
2020

Keyword: Tenaga
Kerja Wanita,
Penawaran
Tenaga Kerja,
Migrasi

\begin{abstract}
Abstrak
Penelitian ini berjudul : "Analisis Penawaran Tenaga Kerja Wanita Migran Kabupaten Sumbawa". Peningkatan jumlah penduduk dari tahun ketahun memiliki beberapa konsekuensi logis diantaranya semakin bertambahnya jumlah penduduk berusia muda dan peningkatan jumlah angkatan kerja. Data Badan Pusat Statistik Kabupaten Sumbawa menunjukkan bahwa selama tahun 2014 sampai tahun 2017 terjadi peningkatan jumlah penduduk berturut-turut 427.119 jiwa, 431.924 jiwa, 436.599 jiwa dan 441.102 jiwa yang tersebar pada 24 kecamatan yang ada. Mata pencarian sebagian besar penduduk (sekitar $52,72 \%$ ) mengantungkan hidup dari sektor pertanian (BPS Kabupaten Sumbawa 2017). Kondisi geografis daerah Kabupaten Sumbawa yang tingkat kesuburannya tidak merata dan curah hujan yang turun juga kurang mencukupi untuk mengembangkan pertanian secara normal, peluang kerja sulit, pendidikan tidak memadai, keterampilan (skill) minim, ketiadaan modal usaha memaksa para penduduk (khususnya wanita) memilih mencoba mencari pekerjaan menjadi tenaga kerja Indonesia ke berbagai Negara termasuk ke Uni Emirat Arab. Tujuan penelitian ini adalah: 1) Bagaimana pola penawaran tenaga kerja wanita asal Kabupaten Sumbawa? 2) Faktor-faktor yang mempengaruhi keputusan berangkat wanita asal Kabupaten Sumbawa menjadi TKW keluar negeri?

Penelitian ini dilaksanakan pada 4 Kecamatan dari 24 Kecamatan yang ada. Masingmasing kecamatan diambil 2-3 desa yang menjadi basis tenaga kerja wanita migran (tergantung jumlah tenaga kerja migran yang ada saat dilakukan survey). Empat Kecamatan yang ditentukan sebagai tempat pengambilan sampel adalah Kecamatan Sumbawa, Kecamatan Plampang, Kecamatan Labuan Badas dan Kecamatan Utan dengan menggunakan metode deskriptif dan pengumpulan datanya dilakukan dengan teknik observasi dan wawancara. Penentuan responden dilakukan dengan teknik purposive sampling.
\end{abstract}

Keluaran penelitian ini adalah dengan diketahuinya pola penawaran tenaga kerja wanita asal Kabupaten Sumbawa dan faktor-faktor yang mempengaruhi keputusan berangkat wanita asal Kabupaten Sumbawa menjadi TKW keluar negeri, sehingga dapat diketahui bagaimana dampak dari bekerja di luar negeri bagi tenaga kerja wanita dan keluarganya serta kontribusinya terhadap Kabupaten Sumbawa secara umum. Selain itu keluaran dari penelitian ini adalah dipublikasikan pada jurnal yang ber ISSN serta dijadikan refrensi bahan ajar pada mata kuliah Ekonomi Makro.

TKT dalam penelitian ini adalah dimulai dengan mengidentifikasi bagaimana pola penawaran tenaga kerja wanita asal Kabupaten Sumbawa dan faktor yang mempengaruhi keputusan berangkat wanita asal Kabupaten Sumbawa menjadi TKW ke luar yaitu dengan metode wawancara dan menyebarkan angket kuesioner. Dengan diketahuinya pola penawaran tenaga kerja wanita dan faktor yang mempengaruhi keputusan tenaga kerja wanita bekerja ke luar negeri dapat menjadi masukan untuk pemerintah apa yang akan dilakukan terhadap tenaga kerja wanita yang bekerja di luar negeri dan memberikan kontribusi terhadap Kabupaten Sumbawa.

\section{PENDAHULUAN}

Peningkatan jumlah penduduk dari tahun ketahun memiliki beberapa konsekuensi logis diantaranya semakin bertambahnya jumlah penduduk berusia muda. Tingginya jumlah penduduk berusia muda mendorong peningkatan jumlah angkatan kerja. Data Badan Pusat Statistik
Kabupaten Sumbawa menunjukkan bahwa selama tahun 2014 sampai tahun 2017 terjadi peningkatan jumlah penduduk berturut-turut 427.119 jiwa, 431.924 jiwa, 436.599 jiwa dan 441.102 Jiwa yang tersebar pada 24 kecamatan-kecamatan yang ada. Apabila di breakdown berdasarkan jenis kelamin maka jumlah penduduk perempuan 216.128 jiwa dan 224.974 jiwa pada tahun 2017 (BPS Kabupaten 
Sumbawa 2017). Berdasarkan mata pencarian penduduk Kabupaten Sumbawa 52,72 \% hidup dari sektor pertanian, $17,79 \%$ hidup dari sektor perdagangan, 13,97 \% hidup dari sektor jasa, 9,79 hidup dari sektor lainnya dan $5,72 \%$ hidup dari sketor indsutri..

Sektor pertanian menjadi mata pencaharian lebih dari setengah penduduk Kabupaten Sumbawa. Kondisi geografis daerah Kabupaten Sumbawa ini yang tingkat kesuburannya tidak merata dan curah hujan yang turun juga kurang mencukupi untuk mengembangkan pertanian secara normal menjadikan sebagian daerah ini hanya mampu bercocok tanam padi rata-rata satu tahun sekali, selain itu mereka juga menanam beberapa tanaman lain sebagai selingan tanaman padi.

Dengan kondisi seperti ini banyak penduduk yang mengantungkan hidupnya pada pertanian tidak bisa berbuat banyak dan akhirnya mereka terjebak pada kemiskinan. Berusaha mencari sumber pendapatan lainnya tampaknya sulit dilakukan hal ini disebabkan karena peluang kerja kerja sulit, pendidikan tidak memadai, keterampilan (skill) minim, ketiadaan modal usaha memaksa para penduduk (khususnya wanita) memilih mencoba mencari pekerjaan menjadi tenaga kerja Indonesia ke berbagai Negara. Mujiayadi (1995) juga mengatakan bahwa alasan utama mengapa orang memutuskan memutuskan melakukan migrasi adalah adanya perbedaan ekonomi, sosial politik, bencana alam dan banyak faktor lainnya. Namun umumnya migrasi lebih dipandang sebagai fenomena ekonomi (hal tersebut merupakan tujuan untuk membedakan migrasi dan aliran pengungsi).

\subsection{Rumusan Masalah}

Berdasarkan uraian latar belakang diatas, dapatlah dirumuskan beberapa rumusan masalah:

1. Bagaimana pola penawaran tenaga kerja wanita asal Kabupaten Sumbawa?

2. Faktor-faktor yang mempengaruhi keputusan berangkat wanita asal Kabupaten Sumbawa menjadi TKW keluar negeri?

1.2. Tujuan Penelitian

1. Bagaimana pola penawaran tenaga kerja wanita asal Kabupaten Sumbawa

2. Faktor-faktor yang mempengaruhi keputusan berangkat wanita asal Kabupaten Sumbawa menjadi TKW keluar negeri?

\subsection{Urgensi Penelitian}

1. Melalui penelitian ini akan memberikan informasi mengenai pola penawaran tenaga kerja wanita asal Kabupaten Sumbawa.

2. Penelitian ini akan memberikan informasi mengenai Faktor-faktor yang mempengaruhi keputusan berangkat wanita asal Kabupaten Sumbawa menjadi TKW keluar negeri.

\subsection{Spesifikasi Penelitian}

Adapun spesifikasi dalam penelitian ini adalah hanya terbatas pada bagaimana pola penawaran tenaga kerja wanita asal Kabupaten Sumbawa faktor-faktor yang mempengaruhi keputusan berangkat wanita asal Kabupaten Sumbawa menjadi TKW keluar negeri dan bagiamana dampak dari bekerja di luar negeri bagi tenaga kerja wanita dan keluarganya serta kontribusi terhadap Kabupaten Sumbawa Secara umum?

\subsection{Luaran Penelitian}

Hasil yang ingin dicapai dalam penelitian ini yaitu dengan diketahuinya bagaimana pola penawaran tenaga kerja wanita asal Kabupaten Sumbawa faktor-faktor yang mempengaruhi keputusan berangkat wanita asal Kabupaten Sumbawa menjadi TKW keluar negeri? Bagaimana dampak dari bekerja di luar negeri bagi tenaga kerja wanita dan keluarganya serta kontribusi terhadap Kabupaten Sumbawa secara umum?

\section{LANDASAN TEORI}

\subsection{Migrasi}

Perpindahan penduduk antar daerah atau bahkan lintas negara tidak bisa dilepaskan dari kondisi sosial ekonomi suatu negara. Kofi Annan, mantan Sekjen Perserikatan Bangsa Bangsa menyatakan bahwa migrasi merupakan masalah dilematis yang sangat sulit dikendalikan, apakah itu migrasi desa ke kota, kota ke kota ataupun Negara ke Negara. Sehingga yang terpenting adalah bagiamana kondisi tersebut dapat dikelolah dengan baik bukan bagimana menghentikannya, karena untuk menghentikan migrasi adalah suatu hal yang tidak mungkin.

Pakar ilmu sosial melihat migrasi (mobilitas penduduk) merupakan jawaban suatu pertanyaan mengenai mengapa penduduk memutuskan pindah atau mempertahankan hidup (Wilkinson : 1973; Broek, Julien Van Den: 1996). Proses mempertahankan hidup harus dilihat dalam arti yang luas dari sisi ekonomi, sosial, politik maupun budaya. Aliran neocalssical economic menyatakan perpindahan penduduk merupakan keputusan pribadi yang didasarkan atas keinginan untuk mendapatkan kesejahteraan yang maksimum. Sedangkan aliran new economics of migration berpendapatan bahwa perpindahan penduduk bahwa perpindahan penduduk bukan hanya karena pasar kerja, namun juga terkait lingkungan sekitar, utamanya lingkungan keluarga (Taylor; 1968; Stark 1991). 
Konsekuensi terjadinya migrasi lintas Negara (internasional migration) oleh banyak penduduk laki-laki memberi dampak bagi meningkatkan peran wanita. Migrasi laki-laki dalam jangka waktu yang lama mengakibatkan subtitusi pekerjaan laki-laki oleh wanita, wanita terpaksa mengerjakan pekerjaan-pekerjaan yang berkaitan dengan pengambilan keputusan dalam keluarga, hugo (1995).

\subsection{Teori Faktor Pendorong dan Penarik (Push and Pull Factor Theory)}

Lee (1970), menyatakan ada empat faktor penyebab orang melakukan migrasi:

1. Faktor yang ada daerah asal

2. Faktor yang terdapat didaerah tujuan

3. Rintangan-rintangan pengahmbat

4. Faktor-faktor pribadi

Faktor yang ada didaerah asal maupun di daerah tujuan bias bersifat positif, negative dan netral terhadap migrasi.

Muljiyadi (1995) menjelaskan lebih rinci mengenai push and pull theory, yaitu faktor-faktor pedorong migrasi meliputi:

1. Tekanan demografi, khususnya populasi angkatan kerja yang tinggi dengan kesempatan (lapangan kerja) dan infrastruktur yang tidak mencukupi untuk menampung.

2. Pendapatan yang rendah di daerah asal meningkatkan probabilitas seseorang untuk pindah mencari pendapatan yang lebih tinggi.

3. Sumber daya yang rendah pada negara miskin menyebabkan penduduk produktif pindah mencari penghidupanyang lebih baik.

4. Faktor lingkungan seperti banjir, kekeringan dan bencana alam menyebabkan migrasi baik sementara atau permanen

5. Kondisi sosial ekonomi yang tidak stabil menyebabkan seseorang tidak bisa bekerja secara aman juga mendorong orang pindah mencari tempat yang lebih aman

Secara umum faktor-faktor penarik pada push-pull theory meliputi:

1. Negara kaya yakni negara industri ataupun negara kaya minyak sangat menarik bagi penduduk negara miskin ataupun negara sedang berkembang.

2. Perbedaan upah yang besar antara negara antara negara asal dengan negara tujuan. Sangat menarik bagi seseorang untuk melakukan migrasi. Tingkat upah yang tinggi dengan jenis pekerjaan dan durasi yang sama akan menarik banyak orang mendapatkannya.

3. Kurangnya tenaga kerja untuk memenuhi kebutuhan tenaga kerja suatu negara perlahan akan memerlukan tenaga kerja migran. Negara-negara kaya minyak akan memperoleh banyak keuntungan mempekerjakan pekerja migran dengan upah rendah.

4. Para pekerja migran terdahulu berpotensi besar menjadi penarik pekerja lain di daerah asalnya, baik itu keluarga, saudara ataupun teman.

\subsection{Teori "Expected Income"}

Migrasi disebabkan oleh faktor ekonomi merupakan salah satu asumsi yang muncul. Todaro (2004) mengatakan bahwa migrasi terjadi karena adanya perbedaan pendapatan. Meskipun keputusan migrasi tidak semuanya rasional, Todaro mengasumsikan bahwa keputusan migrasi merupakan fenomena ekonomi. Model tersebut disebut Expected Income of Rural Urban Migration. Secara matematis merumuskan.

$$
\mathrm{E}(\mathrm{WU})=\mathrm{Wu} *(\mathrm{Eu} / \mathrm{Lu})
$$

Dimana: di kota

$\mathrm{E}(\mathrm{Wu})$ adalah pendapatanyang diharapkan Wu adalah tingkat upah di kota yang lebih tinggi

Eu adalah jumlah pekerjaan di kota

Lu adalah jumlah angkatan kerja di kota

Karakter dasar dalam migrasi meliputi:

1. Pertimbangan ekonomi rasional terhadap keuntungan dan kerugian sebagai pendorong utama melakukan migrasi.

2. Keputusan migrasi lebih bergantung kepada harapan dari pada perbedaan upah riil sesungguhnya yang terdapat di desa dan kota.

3. Kemungkinan seseorang mendapatkan pekerjaan di kota berbanding terbalik dengan pengangguran yang terdapat di kota tersebut.

4. Tingkat migrasi melebihi tingkat pertumbuhan lapangan pekerjaan di kota adalah suatu yang logis.

Teori yang dikemukakan Todaro tersebut hanya berlaku untuk migrasi internal sehingga untuk migrasi eksternal harus dilakukan penyesuaian sebagai berikut:

Dimana:

$$
\mathrm{E}(\mathrm{Wf})=\mathrm{Wf} *(\mathrm{Ef} / \mathrm{Lf})
$$

di luar negeri

E (Wf) adalah pendapatan yang diharapkan lebih tinggi

Wf adalah tingkat upah di luar negeri yang

Ef adalah jumlah pekerjaan di luar negeri

Lf adalah jumlah angakatan kerja diluar negeri

\subsection{Teori Lewis}

Lewis (1954) mengembangkan model pembangunan yang merupakan model pembangunan pertama yang dengan implisit 
memperhatikan proses mobolisasi tenaga kerja dari desa ke kota. Kemudian diperbaharui oleh Jhon C. Fei dan Gustav Ranis (1964). Model 2 sektor lewis merupakan teori "umum" proses pembangunan negraa sedang berkembang yang memiliki surplus tenaga kerja.

Model Lewis membagi perekonomian menjadi 2 sektor tradisional (pedesaan dan subsistem) yang ditandai oleh produktivitas tenaga kerja yang rendah atau bahkan nol, dan sektor modern dimana tenaga kerja dari pedesaan berpindah secara berlahan. Perhatian utama model tersebut adalah proses perpindahan tenaga kerja dan pertumbuhan tingkat penyerapan tenaga kerja pada sektor modern. Hal pentimg lainnya dalam analisis Lewis adalah digunakan asumsi dasar bahwa surplus tenaga kerja terjadi di smeua sektor terutama di sektor subsistem (pertanian).

\subsection{Teori Keputusan Bekerja (Theory of the Decision to Work)}

Keputusan untuk bekerja merupakan keputusan mengenai bagaimana memanfaatkan waktu. Salah satu cara untuk menggunakan waktu adalah untuk aktivitas santai/bersenang-senang. Cara lain yang banyak dilakukan untuk memanfaatkan waktu adalah untuk berkerja.

Domsuch, Fischer dan Startz (2001), mengemukakan bahwa upah riil setelah pajak akan mempengaruhi penawaran tenaga kerja, tetapi untuk orang yang sudah bekerja upah riil yang lebih tinggi memiliki efek ganda pada penawaran tenaga kerja. Efek subtitusi upah yang lebih tinggi mendorong orang bekerja lebih lama, sedangkan efek pendapatan mendorong orang akan lebih memilih menggunakan waktunya untuk bersantai (leasure). Efek ambigu ini tidak terdapat pada orang yang tidak bekerja, sehingga pada kasus ini hanya berlaku efek subtitusi. Jery Hausman dari MIT menyatakan bahwa efek agregat dari peningkatan upah riil setelah pajak secara siginifikan meningkatkan penwaran tenaga kerja, yang sebagian mendorong lebih banyak orang masuk menjadi angkatan kerja.

\subsection{Teori Human Capital}

Upah yang diterima setiap pekerja akan bervariasi tergantung pekerjaan yang mereka lakukan. Tingkat pendidikan merupakan faktor penting dalam menentukan tingkat upah yang diterima. Semakin tinggi pendidikan maka tingkat upah yang akan diterima juga semakin tinggi. Nacrawi dan Usman (2002) menguraikan bahwa faktor-faktor seperti pengalaman, pendidikan formal, profesi jenis kelamin dan kelompok etnik dapat mempengaruhi tingkat upah. Pendidikan merupakan salah satu faktor yang menentukan tingkat upah. Semakin tinggi pendidikan maka tingkat upah yang akan diterima juga semakin tinggi. Pendidikan secara garis besar dibagi menjadi dua yaitu pendidikan formal dan pendidikan tidak formal yang disebut pelatihan (Training). Selain itu ada faktor lain seperti umur, jenis pekerjaan, resiko pekerjaan juga mempengaruhi tingkat upah serta faktor-faktor lain yang mempengaruhi tingkat upah yang terkadang sulit untuk dijelaskan.

\section{MATODE PENELITIAN}

\section{Lokasi Penelitian}

Lokasi penelitian dilakukan di Kabupaten Sumbawa dengan mengambil 4 Kecamatan dari 24 Kecamatan Yang ada. Masing-masing kecamatan diambil 2-3 desa yang menjadi basis tenaga kerja wanita migran (tergantung jumlah tenaga kerja migran yang ada saat dilakukan survey). Empat Kecamatan yang ditentukan sebagai tempat pengambilan sampel adalah Kecamatan Sumbawa, Kecamatan Pelampang, Kecamatan Labuan Badas dan Kecamatan Utan.

\subsection{Peubah yang Diamati}

Adapun peubah yang akan diamati dalam penelitian ini adalah tenaga kerja wanita migran yang memutuskan untuk bekerja diluar negeri (Uni Emirat Arab). Keputusan bekerja diluar negeri dipengaruhi oleh Umur, Status pernikahan, Pendidikan, Pendapatan, Jumlah tanggungan.

\subsection{Model Penelitian}

Model yang digunakan dalam penelitian ini yaitu dengan menggunakan metode deskriptif, yaitu suatu metode yang bertujuan untuk memecahkan masalah yang ada pada saat sekarang dengan cara mengumpulkan, menyusun, menganalisa dan menginterpretasikan data untuk mencapai kesimpulan.

\subsection{Teknik Pengumpulan Data}

Proses pengumpulan data dalam penelitian ini menggunakan teknik pengumpulan data dilakukan dengan teknik survei, yaitu dengan mengumpulkan data dari sejumlah individu (unit sampling) dalam waktu yang bersamaan untuk menggambarkan keadaan populasi dengan menggunakan daftar pertanyaan (quisioner) terstruktur yang telah dipersiapkan sebelumnya.

\subsection{Analisis Data}

Berikut disajikan teknik analisis untuk menjawab setiap pertanyaan dalam rumusan masalah dan tujuan dalam penelitian ini.

1. Analisis diskriptif

Analisis diskriptif merupakan alat analisis sederhana namun mampu menjelaskan dan menjelsakan kondisi riil yang ada. Analsis diskriptif ditampilkan dalam bentuk tabel, grafik dan pengeolahan data yang bersifat interpretasi data.

2. Analsis Regresi Logistik

Model regresi logistik merupakan model regresi untuk menganalisis data dengan variabel dependen berupa variabel dikotomus (bernilai 1 dan 0 ).. $\mathrm{Y}=1$ 
menyatakan keputusan berangkat menjadi tenaga kerja migran dan $\mathrm{y}=0$ menyatakan keputusan tidak bernagkat menjadi tenaga kerja migran. Peubah tersebut mengikuti sebaran bernaulli, sedangkan variabel independen merupakan campuran variabel diskrit, variabel dikotomus dan variabel kontinu (Kuncoro, 2004)

Model persamaan regresi logitsik yang digunakan sebagai berikut:

$L i=\operatorname{Ln}\left(\frac{P i}{1}-P i\right)=\beta 0+\beta 1 U M+$

$\beta 2 \mathrm{M}+\beta 3 P D+\beta 4 I K+\beta 5 J K+\varepsilon$

Dimana :

$\mathrm{P}$ adalah probabilitas seorang wanita memilih nilai variabel dependen (1: berangkat menjadi TKW dan 0: tidak berangkat/belum)

UM adalah umur responden

$\mathrm{M}$ adalah Status pernikahan (dummy; 0: belum menikah, 1: menikah/sudah pernah menikah(janda))

PD adalah Pendidikan (dummy; 0 : SMP atau sederajat pendidikan lebih rendah, 1: SMU atau derajat pendidikan lebih tinggi) IK adalah Pendapatan keluarga yaitu pendapatan yang diperoleh anggota keluarga yang bekerja saat responden belum berangkat menjadi tenaga kerja wanita yang dikategorikan menjadi pendapatan kurang dari Rp 560.000 dan lebih dari Rp 560.000

JK adalah jumlah keluarga yang ditanggung

E adalah error term.

\section{HASIL DAN PEMBAHASAN}

\section{Analisis Diskriptif}

Analisis diskriptif ini menunjukkan gambaran bagaimana keputusan menjadi tenaga kerja para responden melalui analisis terkait status pernikahan, umur, pendidikan, jumah pendapatan dan tanggungan keluarga, serta tabulasi distribuis persentase.

1. Status Perkawinan dan Keputusan Menjadi Tenaga Kerja

Status pernikahan merupakan kondisi seorang wanita terikat dalam suatu keluarga untuk dapat mengatur rumah tangga mereka bekerja sama dengn suami. Namun kondisi saat ini sudah sangat memungkinkan banyak wanita yang telah menikah untuk dapat bekerja disamping mengelolah rumah tangga dan mengaur pengasuhan dan pendidikan anak mereka. Berdasarkan sampel jumlah wanita yang sudah menikah/pernah menikah sebanyak 65 orang dan yang belum menikah sebanyak 35 orang dan yang belum menikah 20 orang berangkat menjadi TKW dan 15 orang tidak berangkat, sedangkan dari 65 orang yang menikah 44 orang memutuskan berangkat mejadi TKW sedangkan 21 orang tidak berangkat. Bagi wanita menikah maupun belum menikah yang saat ini memutuskan untuk tidak bernagakt sangat berpeluang dimasa yang akan dattang menjadi TKW, hal ini dimungkinkan karena pengaruh faktorfaktor lain.

\section{Gambar 1 Status Pernikahan dan}

Berangkat $\square$ Tidak Berangkat

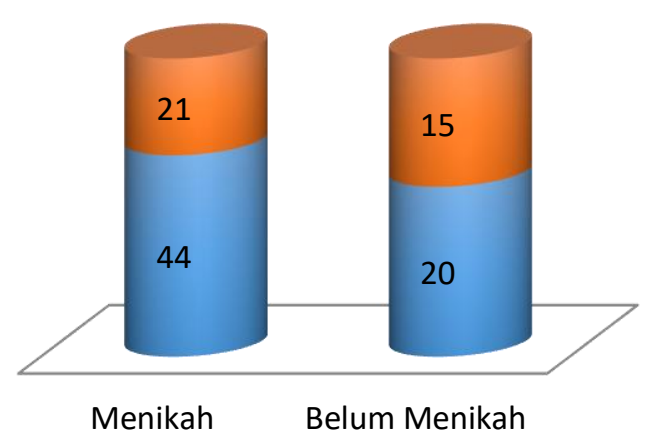

Keputusan Berangkat

Sumber : data primer diolah

\section{Umur dan Keputusan Menjadi Tenaga Kerja}

Umur menunjukkan bagaimana secara fisik dan psikis dalam melakukan aktivitas. Untuk pekerjaan fisik umur memegang peranan penting seseorang mampu menunjukkan produktifitas yang bak untuk melakukan pekerjaan. Produktivitas untuk pekerjaan sektor informal diukur dari seberapa kuat, lama dan terampil pekerja dapat melakukan pekerjaan yang mengandalkan fisik. Menurut Undang-Undang No.39 tahun 2004 tentang penempatan dan perlindungan tenaga kerja Indonesia diluar negeri pasal 35 menyatakan usia minimal bagi calon TKI adalah 18 tahun untuk calon TKI yang bekerja pada perseorangan minimal 21 tahun.

Berdasarkan data diperoleh bahwa umur responden saat akan berangkat pertama kali menjadi TKW adalah 19 sampai 42 tahun sementara untuk responden yang memilih untuk tidak berangkat, berusia antara 18 sampai 49 tahun. Rentang usia responden yang berangkat dan yang tidak berangkat masih berada pada usia produktif yaitu rentang usia 15 tahun sampai 64 tahun.

Tabel 1. Usia dan Keputusan Berangkat 


\begin{tabular}{|l|c|c|c|}
\hline & $\begin{array}{c}\text { Usia } \\
\text { Minima } \\
\text { l }\end{array}$ & $\begin{array}{c}\text { Usia } \\
\text { Maksima } \\
\text { l }\end{array}$ & $\begin{array}{c}\text { Nilai } \\
\text { Modu } \\
\text { Sod }\end{array}$ \\
\hline $\begin{array}{l}\text { Berangka } \\
\mathrm{t}\end{array}$ & 19 & 42 & $\begin{array}{c}23 \text { dan } \\
30\end{array}$ \\
\hline $\begin{array}{l}\text { Tidak } \\
\begin{array}{l}\text { Berangka } \\
\mathrm{t}\end{array}\end{array}$ & 18 & 49 & 28 \\
\hline
\end{tabular}

Sumber : data primer diolah

3. Tanggungan dan Keputusan Menjadi Tenaga Kerja

Jumlah tanggungan keluarga yang dimaksud dalam penelitian ini adalah jumlah anggota keluarga responden yang terdiri dari anak-anak serta orang lain yang hidup dan makan baik dalam satu rumha ataupun tidak sepenuhnya menjadi tanggungan responden.

Jumlah tanggungan responden yang berangkat menjadi TKW atara 1-5 orang dan untuk mereka yang tidak bernagkat jumlah tanggungan antara 1-2 orang.

4. Pendapatan dan eputusan Menjadi tenaga kerja

Pendapatan merupakan suatu prefrensi yang penting bagi calon TKW. Pendapatan yang lebih tinggi diluar negeri dibandingkan degan bekerja dengan jenis pekerjaan yang sama didalam negeri memnjadi daya tarik tersendiri bagi TKW. Mayoritas responden menyatakan tertarik terhadap tingkat pendapatan yang lebih tinggi bekerja di luar negeri. Kondisi ini sejlan dengan dengan teori push and pull. Dimana faktor pendpatan yang rendah didaerah asal memberi dorongan para wanita melakukan migrasi dari daerah asal untuk mencari kehidupan yang lebih layak. Sedangkan faktor penariknya adalah tingkat pendapatan yang lebh tinggi yang dapat diperoleh didaerah tujuan.

Tabel 2. Pendapatan dan Keputusan

\begin{tabular}{|l|c|c|}
\hline & $\begin{array}{c}\text { Berangkat } \\
\text { Dibawah } \\
(<\mathbf{R p} \\
\mathbf{5 6 0 . 0 0 0})\end{array}$ & $\begin{array}{c}\text { Diatas } \\
(>\mathbf{R p} \\
\mathbf{5 6 0 . 0 0 0})\end{array}$ \\
\hline Berangkat & 50 & 14 \\
\hline Tidak & 15 & 21 \\
Berangkat & & \\
\hline
\end{tabular}

Sumber : data primer diolah

5. Pendidikan dan Keputusan Menjadi Tenaga Kerja

Secara keseluruhan tingkat pendidikan responden yang berpendidikan yang berpendidikan SMP kebawah sebanyak 52 dan 48 responden SMU ke atas. Dari 52 responden berpendidikan di bawah SMP, 23 memutuskan bernagkat dan 29 responden tidak berangkat. Sedangkan dari 48 responden pendidikan SMU atau lebih tinggi, 41 responden berangkat menjadi TKW dan 7 responden tidak berangkat.

Responden dengan tingkat pendidikan SMU atau lebih memilih beragkat karena mereka sudah sulit untuk mendapatkan pekerjaan dengan ijasah SMU atau lebih.

Tabel 3. Pendapatan dan Keputusan Berangkat

\begin{tabular}{|c|c|c|}
\hline Pendidikan & Berangkat & $\begin{array}{c}\text { Tidak } \\
\text { Berangkat }\end{array}$ \\
\hline <SMP & 23 & 29 \\
\hline >SMU & 41 & 7 \\
\hline
\end{tabular}

Sumber : data primer diolah

\section{B. Regresi Logistik}

1. Uji Goodnes Of Fit

Uji ini dilakukan untuk mengetahui apakah model yang digunakan sudah fit atau tidak. uji yang dilakukan untuk mengetahui kebaikan model adalah uji Hosmer and Lemeshow Test. Adapun hasil ujinya dapat dilihat pada table dibawah ini.

Hosmer and Lemeshow Test

\begin{tabular}{|l|r|r|c|}
\hline Step & Chi-square & \multicolumn{1}{c|}{ df } & \multicolumn{1}{c|}{ Sig. } \\
\hline 1 & 5.735 & 3 & .125 \\
2 & 4.942 & 5 & .423 \\
\hline
\end{tabular}

Berdasarkan tabel diatas diketahui bahwa nilai chi square pada step 2 adalah sebesar 4,942 dengan nilai signifikan sebesar 0,423 lebih dari 0,05 . Hal ini dapat dikatakan bahwa model dapat dikatakan fit dan model dapat diterima dan digunakan.

\section{Uji Simultan}

Uji simultan ditujukan untuk mengetahui apakah terdapat pengaruh variabel-variabel bebas secara bersamaan terhadap variabel y. uji yang digunakan adalah uji Omnibus Test. Adapun hasil ujinya dapat dilihat pada table dibawah ini.

Omnibus Tests of Model Coefficients

\begin{tabular}{|c|c|c|c|c|}
\hline & & Chi-square & $\mathrm{df}$ & Sig. \\
\hline \multirow{4}{*}{ Step 1} & Step & 14.798 & 1 & .000 \\
\hline & Block & 14.798 & 1 & .000 \\
\hline & Model & 14.798 & 1 & .000 \\
\hline & Step & 4.552 & 1 & .033 \\
\hline \multirow[t]{2}{*}{ Step 2} & Block & 19.350 & 2 & .000 \\
\hline & Model & 19.350 & 2 & .000 \\
\hline
\end{tabular}

Berdasarkan pada table diatas dapat diketahui bahwa nilai signifikansi model pada step 2 sebesar 0,000 kurang dari 0,05 maka dapat disimpulkan bahwa terdapat pengaruh variabel $\mathrm{x}$ secara bersama-sama terhadap variabel $\mathrm{y}$. 


\section{Uji Parsial}

Uji parsial dilakukan untuk mengetahui pengaruh varibel bebas secara langsung terhadap variabel y adapaun hasil ujinya dapat dilihat pada table dibawah ini untuk tidak berangkat sangat berpeluang dimasa akan datang menjadi TKW.

2. Umur responden saat akan berangkat pertama kali menjadi TKW adalah 19-42 tahun masuk pada usia produktif

Variables in the Equation Hasil reoresi looistic menuniukkan hahwa

\begin{tabular}{|c|c|}
\hline & \\
\hline Step $1^{\mathrm{a}}$ & $\begin{array}{l}\text { J_TANGGUNGAN } \\
\text { Constant } \\
\text { PENDIDIKAN(1) }\end{array}$ \\
\hline Step $2^{b}$ & $\begin{array}{l}\text { J_TANGGUNGAN } \\
\text { Constant }\end{array}$ \\
\hline
\end{tabular}

\begin{tabular}{l|l} 
B & S.E.
\end{tabular}

\begin{tabular}{r|r|}
.590 & .169 \\
-1.177 & .547 \\
1.013 & .486 \\
.669 & .180 \\
-1.995 & .703 \\
\hline
\end{tabular}

a. Variable(s) entered on step 1: J_TANGGUNGAN.

b. Variable(s) entered on step 2: PENDIDIKAN.

Berdasarkan pada table diatas dapat diketahui bahwa nilai signifikasi varibel pendidikan sebesar 0,037 kurang dari 0,05 sehingga dapat disimpulkan bahwa terdapat pengaruh pendidikan secara signifikan terhadap keberangkatan TKW. Begitu juga dengan variable jumlah tanggungan dimana nilai signifikansinya sebesar 0,000 kurang dari 0,05 yang berarti bahwa terdapat pengaruh signifikan jumlah tanggungan terhadap keberangkatan TKI.

Adapun persamaan model yang dapat digunakan adalah sebagai berikut

$$
\begin{aligned}
& \text { Ln } \frac{p}{1-p} \\
& =-1,995+1,013 \text { Pendidikan } \\
& +0,669 \text { Jumlah tanggungan } \\
& \frac{p}{1-p} \\
& =e^{-1,995} * e^{1,013 \text { Pendidika }} \\
& * e^{0,669 \text { Jumlah tanggungan }}
\end{aligned}
$$

Interperetasi dari model diatas dapat dikatakan dengan semakin tinggi pendidikan dan jumlah tanggungan maka probabilitas untuk berangkat menjad TKI juga semakin tinggi.

\section{PENUTUP}

\section{Kesimpulan}

1. Hasil penelitian menunjukkan bahwa 44 orang memutuskan berangkat menjadi TKW dengan status pernikahan sudah menikah. Bagi wanita menikah maupun belum menikah yang saat ini memutuskan

\section{REFERENSI}

Anonim 2017. Kabupaten Sumbawa Dalam Angka Tahun 2017. Sumbawa : Badan Pusat Statistik.

Borjas, George J., 2000. Labor Economics, McGrwa-Hill, New York USA

Dornbusch, Rudiger, Fischer, Stanley; Starz, Richard (2001). Macroeconomics. New York. McGrawHill Education (Edisi Indonesia)

Muljiyadi, B. 1995 . "Female Labour Migration (A Challenge and A Expectation)", Jurnal Penelitian dan Pengembangan Kesejahteraan Sosial, No. 2 (JuliSeptember) pp.39-49

Kuncoro, M, 2004, Metode Kuantitatif, Edisi Kedua, Penerbit Erlangga, Jakarta.

Lee, Everest. S. 1970, A Theory of Migration in Demko, George J. Harold M. Rose and George A. Scanel, Population Geografy: A Reader, New York : McGraw-Hill Book Company.

Nachrowi DN, Hardius Usman. 2002. Penggunaan Teknik Ekonometri, RajaGrafindo Persada, Jakarta

Todaro, M.P. 2004. Pembangunan Ekonomi di Dunia Ketiga. Edisi Kedelapan, Erlangga, Jakarta. 